\title{
Disruptor taxa, oral microbes, and strict anaerobes in the human small-intestine microbiome
}

Jacob Barlow

Gabriela Leite

Anna E. Romano

Rashin Sedighi

Christine Chang

Shreya Celly

Ali Rezaie

Ruchi Mathur

Mark Pimentel

Rustem F. Ismagilov

\section{Video Byte}

Keywords: Microbiome, gastrointestinal, Duodenum, saliva, HACEK, human small intestinal microbiome, IBS, SIBO, Enterobacteriaceae, Lactobacillus, constipation, bloating, GI health, disruptor taxa, anaerobes, small intestine, endoscopy, microbiota, oral microbiome, irritable bowel syndrome, quantitative sequencing, genomics

Posted Date: March 1st, 2022

DOI: https://doi.org/10.21203/rs.3.rs-1405875/v1

License: (c) (i) This work is licensed under a Creative Commons Attribution 4.0 International License.

Read Full License 


\section{Abstract}

Past research has already tied our gut microbiome to many diseases. However, most research to date has focused on the large intestine, as collecting stool samples is less invasive than sampling the small intestine. Recently, researchers used standard-of-care endoscopies as an opportunity to collect samples from the first section of the small intestine, the duodenum. Using quantitative sequencing, they evaluated the patients' microbial loads. They found preliminary evidence of microbes traveling from the mouth to the small intestine, as $89 \%$ of the microbial taxa found in duodenum samples were also present in saliva samples from the same patient. Within the duodenum, the researchers identified a collection of bacterial taxa that, when present, often dominated the microbial population. These 'disruptor taxa' appeared to replace the strict anaerobes common in the duodenum and were more prevalent in individuals with the serious GI disorder small intestinal bacterial overgrowth (SIBO). Higher loads of disruptor taxa were associated with more severe GI symptoms. Further research is needed to determine how these disruptor taxa behave in people without GI disorders and to examine the origins of disruptor taxa and how they influence major GI symptoms. 